\title{
CHANGING MARKET POTENTIALS, REGIONAL GROWTH AND INCOME DISPARITIES IN POLAND
}

\author{
Jesús López-Rodríguez, Malgorzata Runiewicz-Wardyn*
}

\begin{abstract}
:
In this paper we analysed to which extent the changes in market potentials in Poland have been a cause for increasing income disparities, which were observed across Polish regions from 1995 to 2008. To do so we derived and estimated a New Economy Geography Model, which relates per capita GDP growth rates to changes in market potential. The results of the crosssection estimations of the model for the period 1995-2008 and for its different subsamples point to a positive and significant effect of changing market potentials in per capita GDP growth rates. Due to the fact that core-economic regions have mostly benefited in terms of market potential growth during 1995-2008, these results confirm the important role played by the relative changing in market potentials across Polish regions in widening the gap between poor and rich regions in the country in the period of analysis.
\end{abstract}

Keywords: market potential, regional differences, Poland, growth rates

JEL Classification: R11, R12, R13, R14, F12, F23

\section{Introduction}

The idea that market potential is important in determining regional incomes dates back at least to Harris (1954) who approximates a market potential function, which expresses the potential demand for goods produced in a location as the sum of the purchasing power in all surrounding locations, weighted by transport costs. The market-potential function has

* Jesús López-Rodríguez, IPTS-JRC European Commission, Seville, Spain \& Universidad de A Coruña, Campus de Elviña, s/n. C.P.: 15071, A Coruña, Spain (jelopez@udc.es); Malgorzata Runiewizc-Wardyn, Kozminski University, Jagiellonska 59, Warsaw 03-301, Poland (mruniewi@tiger.edu.pl).

The authors want to thank the editors of the journal Josef Arlt and Milan Kolár, and also the PEP anonymous referees whose comments and suggestions have helped to improve the quality of the paper. A substantial part of this paper has been finished while the first author was a visiting scholar at the department of Geography and Environment at the LSE in 2011. The first author thanks professor Rodriguez-Pose for sponsoring his visiting position at LSE. The first author also wants to thank Paulino Montes-Solla for superb research assistance while doing this work.

Financial support from the Spanish Ministry of Science and Innovation through Grant ECO201128632 is gratefully acknowledged. The opinions, analyses and results of this work are the exclusive responsibility of the authors and do not represent the position of the European Commission. The usual disclaimer applies. 
a long history in urban economics, Clark et al. (1969), Dicken and Lloyd (1977), Keeble et al. (1982) focusing instead on the implication for the location of production.

The seminal contributions of Krugman in the early nineties (Krugman, 1991a, 1991b, 1992) within the new field of spatial economics labelled as New Economic Geography (NEG henceforth) has given a revival to this traditional concept in the urban and regional economics literature providing the micro-foundations for Harris (1954) market potential concept. Empirical research within the NEG literature has shown the significance of market potential for the spatial distribution of incomes (Breinlich (2006), LópezRodríguez et al. (2011), Hanson (2005), Redding and Venables (2004)), educational attainment levels (López-Rodríguez et al. (2007), Redding and Schott (2003)) and for industrial location decisions (Midelfart-Knarvik et al., 2002).

Given a set of locations, for instance the sample of NUTS 2 regions ${ }^{1}$ in a country, the market potential of each location depends on the levels of GDP in the home region and the levels of GDP in the surrounding locations within the given set adjusted for their proximity to the home region. Proximity depends on the bilateral distance between the locations that form the set. Relatively low regional market potential can be thought of as that region/s is (are) far from the main consumer markets and therefore in the centreperiphery or core-periphery dichotomy of NEG models can be referred to as "economicperiphery". On the contrary, relatively high regional market potential is associated with proximity to main consumer markets and therefore regions enjoying it are often equated with "centrality" and can be referred to as "economic-centre" or "core-economic" regions. Changes over the course of the years in market potentials can be the result of the difference performance of the regions in terms of economic growth or differences in transport costs over time. However, changes in transport costs should not play a big role in market potential values when short periods of time are considered in the analysis. Only long time spans can make differences in transport costs over time to significantly influence the relative economic-centrality or economic-periphery enjoyed by the regions. For instance over the course of the last century we attended to a very important change in the mode goods are transported from rail and steamships (at the start of the twentieth century) to ferries and trucks (a hundred years later).

In this paper we analyse to which extent the changes in market potentials in Poland have been behind the increasing in income disparities observed across Polish regions from 1995 to 2008. To do so we follow Ottaviano and Pinelli's (2006) paper and we derive and estimate a New Economy Geography Model which relates per capita GDP growth rates with changes in market potential. The results of the estimations of cross-section growth-type regressions for the period 1995-2008 including the changing in market potentials as our key variable show a positive and significant effect of this variable in per capita GDP growth rates. Taking into account the fact that core-economic regions

1 'NUTS' (Nomenclature of Territorial Units for Statistics) is a geographical classification system used by Eurostat, dividing each country into a number of regions at different levels of aggregation. This paper works at the NUTS2-level of aggregation which consists of 16 Polish NUTS2 regions. 
have been the most benefited in terms of market potential growth during 1995-2008, this result therefore confirms the important role played by the changing market potentials across Polish regions in widening the gap between poor and rich regions in the country under the period of analysis. This investigation complements the works carried out by Crafts (2005), Martinez Galarraga (2010) and Ottaviano and Pinelli's (2006) in the literature dealing with the significance of market potential in the growth processes of regions within countries adding new empirical evidence for a country belonging to the block of the so called Central and Eastern European Countries as is the case of Poland.

The remaining part of the paper is structured as follows. Section 2 introduces the Harris (1954) market potential concept and presents some descriptive statistics of market potentials in Poland. Section 3 presents the theoretical framework. Section 4 analyses the relationship between the changing market potential in Poland and per capita GDP growth over the period 1995-2008. Finally in Section 5 we present the main conclusions.

\section{Market Potentials in Poland: A Core-Periphery Pattern}

Harris's (1954) market-potential function relates the potential demand for goods and services produced in a location $j=1,2, \ldots, \phi$ to that location's proximity to consumer's markets: Mathematically, the market potential function in its simplest formulation obeys to the following expression:

$$
M P_{i}=\sum_{j=1}^{\phi} Y_{j} g\left(d_{i j}\right)
$$

where $M P_{i}$ is the market potential of location $i, Y_{j}$ is an index of purchasing capacity of location $j$ (usually gross value added, gross domestic product or population), $d_{i j}$ is the distance between two generic locations $i$ and $j$ and $g(\cdot)$ is a decreasing function. In our case, the $g(\cdot)$ function we have chosen to carry out our market potential computations is the inverse of the distance function so $g(\cdot)=1 / d_{i j}{ }^{2}$ We will compute two measures of market potentials in accordance with the way of proxying the volume of economic activity. Our first measure of market potential takes as a proxy for the volume of economic activities the total gross domestic product in each Polish NUTS 2 region $^{3}$ measured in local currency units and therefore market potential computed in this way would be termed as nominal market potential. Our second measure of market potential takes as a proxy

2 Although other distance decay functions could be used, the vast majority of the empirical analysis based on the use of Harris (1954) market potential concept use inverse of distance functions (LopezRodríguez and Faiña (2007), Niebuhr (2006) among others. However, in another spatial setting Redding and Venables 2004 have compared the performance of the traditional market potential function against more sophisticated functions and the results they reached were very similar.

3 NUTS (Nomenclature of Territorial Units for Statistics) are a nomenclature providing a hierarchical structure of sub-national regions covering all European territory. Eurostat first subdivides countries of the EU into NUTS 1 (corresponding for instance to Comunidades Autónomas in Spain or German Landers in Germany) each of them being divided into several NUTS2 regions. Currently Europe is divided into 97 regions at NUTS 1 level and 271 regions at NUTS 2 level. 
for the volume of economic activities the total gross domestic product in each Polish NUTS 2 region measured in purchasing power parities (PPS) and therefore could be termed as real market potential. ${ }^{4}$ The main implications of these two alternative ways of measuring local GDP is that under the use of nominal GDP values for computing market potential, the importance of the Polish regions located in the so called economy periphery would be underestimated since the prices in the periphery are usually lower than the ones in central locations. Therefore, this distortion is completely eliminated using GDP variables expressed in PPPs. Regarding the calculation of bilateral distances in the market potential function it is made on the basis of the road distances expressed in kilometres between the capital cities of each NUTS 2 region in which Poland is divided. For the calculation of the internal distance within each NUTS 2 region, it is approximated by a function that is proportional to the square root of each regions' area. The expression used is $0.66 \sqrt{\frac{\text { Area }}{\pi}}$, where Area is each region area expressed in squared kilometres $\left(\mathrm{km}^{2}\right)$. This expression gives the average distance between two points on a circular location (see Crozet, 2004; Head and Mayer, 2000 and Nitsch, 2000) for a discussion of this measure of internal distance).

All the data was obtained from the website www.odleglosci.pl and from the Europe institute for official statistics (EUROSTAT).

Taking into account the Harris's (1954) market-potential function, we analyse the distribution of market potentials across the sixteen NUTS 2 regions in which Poland is divided over the period 2000-2008. We started by analyzing the spatial structure of market potentials at the beginning of the period, year 2000 and compare it with the spatial structure in the year 2008. ${ }^{5}$ We have also performed our analysis by dividing the whole period into two sub periods (2000-2004) and (2004-2008) by averaging for each

4 GDP expenditure values are made up of two components: price and volume. Comparing the expenditure values of regions within a country (our case) or across countries will not provide a comparison of the volumes of goods and services purchased in the regions or countries unless the price level differences that exist between them have been eliminated. This is the reason why we resort to the so called GDP figures expressed in PPS (purchasing power standards) or sometimes named PPPs (purchasing power parities). Therefore, PPPs are both currency converters and spatial price deflators. When countries share a common currency, as do the countries of the euro area, there is no need to convert to a common currency and PPPs can be defined simply as spatial price deflators. This definition also applies to PPPs calculated for regions within a country. It is important to recognise that having the same currency does not necessarily mean having the same price level (see Wolszczak-Derlacz, 2010). PPPs are still required. Thus, if the PPP for GDP between Podlaskie and Łódzkie is 0.90, it can be inferred that for every euro spent on the GDP in Łódzkie, 0.90 euros would have to be spent in Podlaskie to purchase the same volume of goods and services.

5 To compute the evolution of market potentials year by year would not add much more insights to the analysis we carry out here due to the fact that the increase in the volume of economic activity which causes the increase in market potential values from one year to the next has to be scaled by the bilateral distances between the different locations and therefore the potential variation in market potentials heavily smoothed. For instance, the calculations imply that if two regions are $100 \mathrm{~km}$ away from each other the scale factor is $1 / 100$ which implies dividing by 100 the increase in the volume of economic activity from one year to the next. 
Polish NUTS 2 region its market potential value over the corresponding sub-period of time. Averaging market potentials over 4 or 5 year-intervals allow us to avoid misleading interpretations in the evolution of the spatial structure due to distortions that could be caused by chosen a year at the pick of the cycle and compare it with another year which is at the bottom of the cycle.

\section{Figure 1}

\section{Market Potential in Poland (2000)}

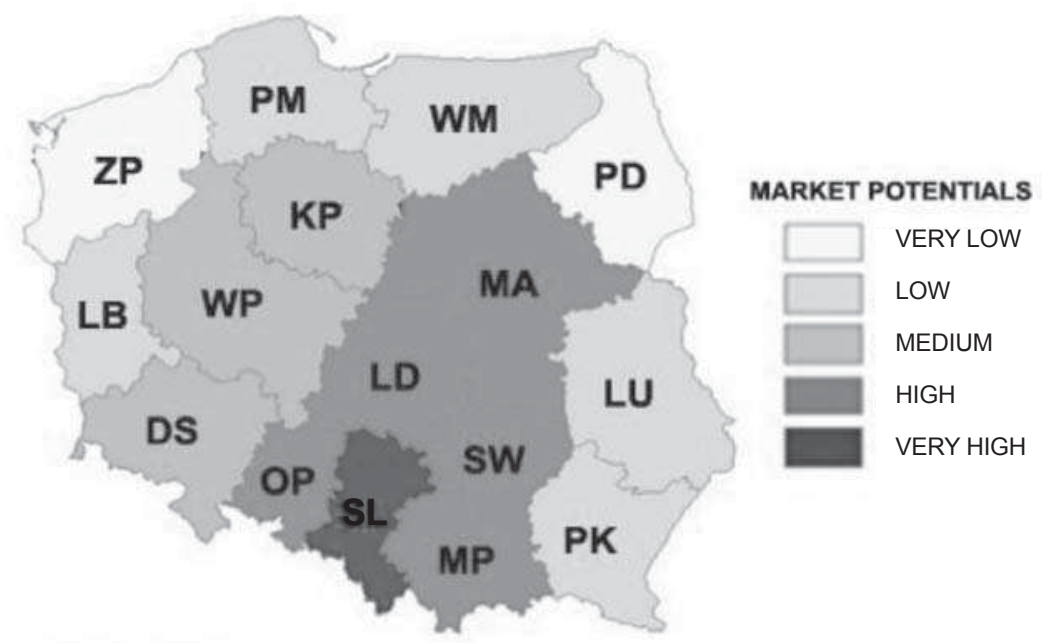

DS: Dolnośląskie; KP: Kujawsko-Pomorskie; LU: Llubelskie; LB: Llubuskie; LD: Łódzkie; MP: Małopolskie; MA: Mazowieckie; OP: Opolskie; PK: Podkarpackie; PD: Podlaskie; PM: Pomorskie; SL: Śląskie; SW: Świętokrzyskie; WM: Warmińsko-Mazurskie); WP: Wielkopolskie; ZP: Zachodniopomorskie

Source: Own elaboration.

Figures 1 and 2 depict the spatial structure of market potentials across NUTS 2 regions in Poland for 2000 and 2008, respectively. Both figures show a well-established core-periphery pattern in the distribution of market potentials across the space. Around the regions that make the so called economic core we can distinguished successive envelopments of regions with decreasing levels of market potential that make the so called economic periphery. Both in 2000 and 2008 the economic core is made of the regions which we labelled as regions with very high and high market potential values according to the map's legend. They are geographically located in the South and Central Eastern parts of the country. These regions are Śląskie, Mazowieckie, Małopolskie, Łódzkie, Świętokrzyskie, Opolskie. Surrounding these regions, the next envelopment of regions labelled as regions with medium market potential values are located on the Western part of the core, Dolnośląskie, Kujawsko-Pomorskie and Wielkopolskie. The regions labelled as low market potential regions made the next envelopment which takes in Lubelskie and Podkarpackie surrounding the Eastern 
side of the core regions and Lubuskie, Pomorskie and Warmińsko-Mazurskie surrounding the Western side of the medium market potential regions. Finally, the very low market potential regions take in the Northwest region of Zachodniopomorskie and the Northeast region of Podlaskie. As we can see from the maps the changes between 2000 and 2008 has taken place only within the so called economic core regions where there was an expansion of the very high market potential regions from only one region in 2000 (Śląskie) to three more regions in 2008 (Mazowieckie, Małopolskie, Łódzkie).

Figure 2

\section{Market Potential in Poland (2008)}

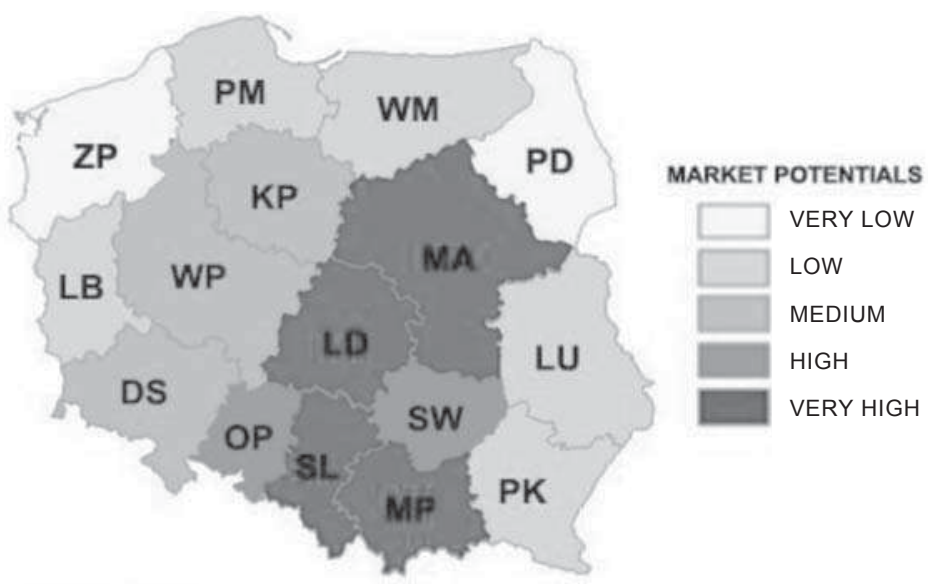

DS: Dolnośląskie; KP: Kujawsko-Pomorskie; LU: Llubelskie; LB: Llubuskie; LD: Łódzkie; MP:

Małopolskie; MA: Mazowieckie; OP: Opolskie; PK: Podkarpackie; PD: Podlaskie; PM: Pomorskie;

SL: Śląskie; SW: Świętokrzyskie; WM: Warmińsko-Mazurskie); WP: Wielkopolskie; ZP:

Zachodniopomorskie

Source: Own elaboration.

The next set of maps (Figures 3 and 4 ) show the distribution of market potentials across Polish regions dividing the whole period of analysis into two sub periods 2000-2004 and 2005-2008 where the market potential for each NUTS 2 regions was computed as an average of the values of the corresponding years of the sub-period.

As it can be seen from Figures 3 and 4 the general conclusions that we have obtained previously comparing 2000 and 2008 are repeated here. There is a strong core-periphery pattern in terms of market potentials across Poland in both periods of analysis and the changes in market potentials from the first period to the second one has taken place only at the level of the regions labelled as very high and high market potential regions (the so called economic core) with the expansion of those regions recording very high market potential values both to the West of Śląskie taking in the Małopolskie region 
where the capital of the region Krakow is placed and to the North of Ślaskie to the regions of Łódzkie and Mazowieckie where the city of Lodz and the capital of the country are located.

\section{Figure 3}

\section{Market Potential in Poland (2000-2004)}

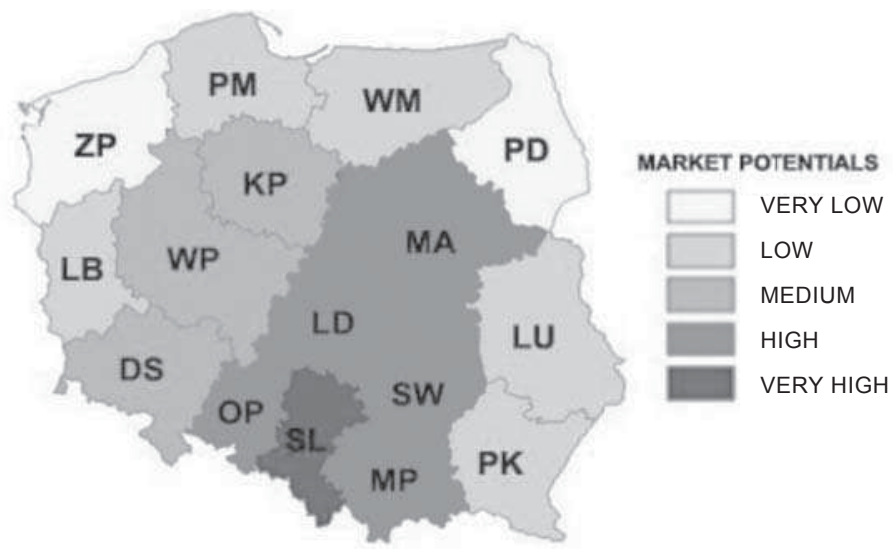

DS: Dolnośląskie; KP: Kujawsko-Pomorskie; LU: Llubelskie; LB: Llubuskie; LD: Łódzkie; MP: Małopolskie; MA: Mazowieckie; OP: Opolskie; PK: Podkarpackie; PD: Podlaskie; PM: Pomorskie; SL: Śląskie; SW: Świętokrzyskie; WM: Warmińsko-Mazurskie); WP: Wielkopolskie; ZP: Zachodniopomorskie

Source: Own elaboration.

Figure 4

Market Potential in Poland (2005-2008)

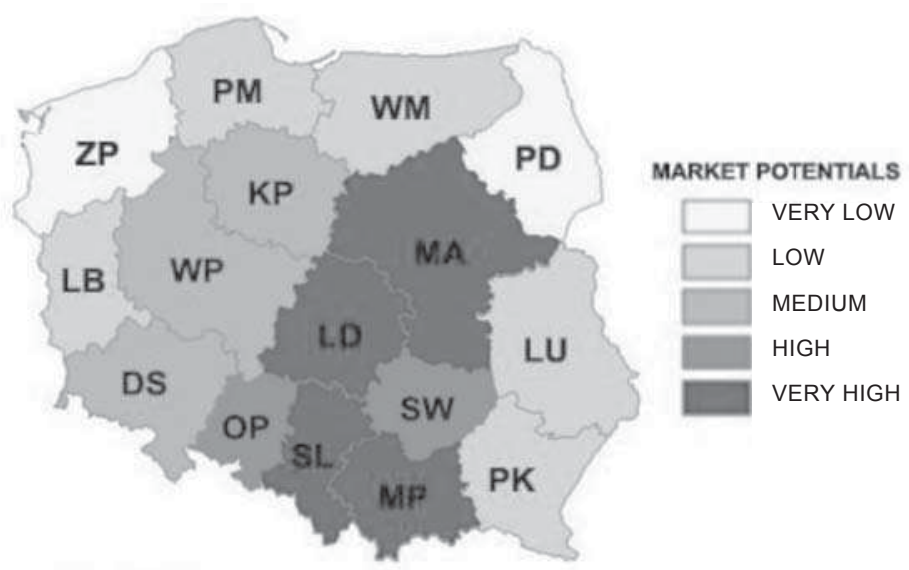

DS: Dolnośląskie; KP: Kujawsko-Pomorskie; LU: Llubelskie; LB: Llubuskie; LD: Łódzkie; MP: Małopolskie; MA: Mazowieckie; OP: Opolskie; PK: Podkarpackie; PD: Podlaskie; PM: Pomorskie; SL: Śląskie; SW: Świętokrzyskie; WM: Warmińsko-Mazurskie); WP: Wielkopolskie; ZP: Zachodniopomorskie

Source: Own elaboration. 
A clearer picture of the winning regions can be seen in the following Figure 5, which depicts the average increases in total market potentials from the period 2000-2004 to the period 2005-2008 for each region.

\section{Figure 5}

Market Potential Increase in Poland from 2000-2004 to 2005-2008

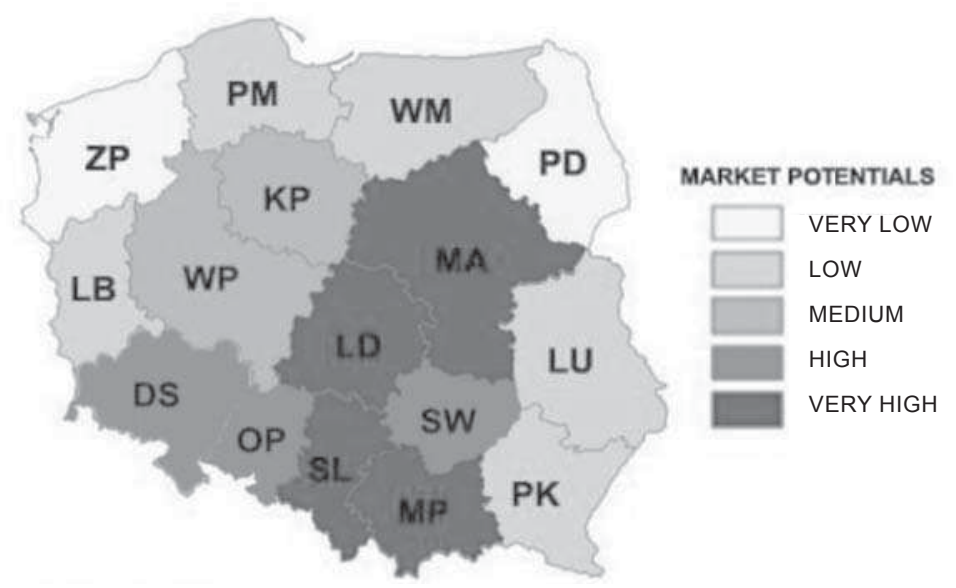

DS: Dolnośląskie; KP: Kujawsko-Pomorskie; LU: Llubelskie; LB: Llubuskie; LD: Łódzkie; MP: Małopolskie; MA: Mazowieckie; OP: Opolskie; PK: Podkarpackie; PD: Podlaskie; PM: Pomorskie; SL: Śląskie; SW: Świętokrzyskie; WM: Warmińsko-Mazurskie); WP: Wielkopolskie; ZP: Zachodniopomorskie

Source: Own elaboration.

As can be seen in Figure 5 those regions that form the economic core of the country have been the ones most benefited from the increase in market potential values over time. Therefore we can conclude that in this 9 year-time span there was a process of reinforcement of the economic core in which several regions with high market potential values have been upgraded to very high market potential values while the regions belonging to the so called economic periphery during 2000-2004 (regions with medium, low and very low market potential values) has not experienced any upgrades in the subsequent period 2004-2008. This process reflects a situation in which the spatial structure of the Polish economic activity over these years has been dominated by the superior effects of the centripetal forces that tend to cluster economic activities together in the so called economy core locations of the country versus centrifugal ones that tend to push them apart to other locations in the economic periphery and other intermediate locations.

A closer look at the evolution of the so called economic core and economy periphery of Poland can be obtained by computing its market potential annual growth rates over the period 2000-2008. The results of these computations are shown in Table 1. The results of these computations show that market potential growth rates in core regions are slightly greater than market potential growth rates in periphery regions. ${ }^{6}$ Given that

6 The only exception is the year 2005 . 
the differences are in the range of 0.1 and 0.2 per cent respectively we could not claim any substantial differences in growth rates. However, these results point to the fact that economic activities tend to cluster in space and therefore are in clear opposition with the conclusions of the neo-classical convergence theories. Moreover, the data shows quite clearly that market potential growth rates have risen quite substantially from 2004 onwards both in core and periphery regions.

Table 1:

Market Potential Growth Rates

\begin{tabular}{|l|c|c|c|c|c|c|c|c|}
\hline Regions & $\mathbf{2 0 0 1}$ & $\mathbf{2 0 0 2}$ & $\mathbf{2 0 0 3}$ & $\mathbf{2 0 0 4}$ & $\mathbf{2 0 0 5}$ & $\mathbf{2 0 0 6}$ & $\mathbf{2 0 0 7}$ & $\mathbf{2 0 0 8}$ \\
\hline Core & 4.6 & 4.0 & 4.4 & 10.0 & 5.9 & 7.8 & 11.1 & 8.8 \\
\hline Periphery & 4.7 & 3.6 & 4.2 & 9.6 & 6.5 & 7.8 & 11.0 & 8.2 \\
\hline Average growth core & \multicolumn{3}{|c|}{4.3} & & \multicolumn{7}{c|}{8.7} \\
\hline Average growth periphery & \multicolumn{3}{|c|}{4.1} & \multicolumn{7}{c|}{} \\
\hline
\end{tabular}

Core: Śląskie, Opolskie, Małopolskie, Łódzkie, Mazowieckie, Świętokrzyski; Periphery: remaining regions Source: Own elaboration

This evolution of market potential growth rates over time in the economic core and economic periphery of Poland could be originated by a difference in prices between these two areas favouring the core regions when we use GDP measured at current prices in our market potential computations. In order to correct for this bias and to get a more accurate picture of market potential growth rates over time we have recomputed growth rates again using GDP adjusted for purchasing power parity (GDP measured in PPS). The results of the computations are downgraded but the qualitative conclusions are the same. Market potential growth rates in Poland economic core regions are higher than in economic periphery regions in both periods of time and once again and important rise in market potential growth rates is observed after 2004. Table 2 shows very clearly the pattern follow by the economic core and economic periphery Polish regions in both periods of time.

Table 2:

Market Potential Growth Rates (GDP measured in PPS)

\begin{tabular}{|l|c|c|c|c|c|c|c|c|}
\hline Regions & $\mathbf{2 0 0 1}$ & $\mathbf{2 0 0 2}$ & $\mathbf{2 0 0 3}$ & $\mathbf{2 0 0 4}$ & $\mathbf{2 0 0 5}$ & $\mathbf{2 0 0 6}$ & $\mathbf{2 0 0 7}$ & $\mathbf{2 0 0 8}$ \\
\hline Core & 2.1 & 5.5 & 2.4 & 8.6 & 4.9 & 6.1 & 10.5 & 4.4 \\
\hline Periphery & 2.1 & 5.1 & 2.3 & 8.1 & 5.2 & 6.2 & 10.4 & 3.8 \\
\hline Average growth core & \multicolumn{3}{|c|}{3.34} & \multicolumn{7}{|c|}{6.9} \\
\hline $\begin{array}{l}\text { Average growth } \\
\text { periphery }\end{array}$ & \multicolumn{3}{|c|}{3.19} & & \\
\hline
\end{tabular}

Core: Śląskie, Opolskie, Małopolskie, Łódzkie, Mazowieckie, Świętokrzyski; Periphery: remaining regions Source: Own elaboration 
Averaging growth rates for 2000-2004 and 2004-2008, growth rates in the latter period more than double those of the former period either using GDP at current prices or GDP measured in PPS. This fact calls for a detailed analysis of the reasons behind this outperformance in terms of market potential growth rates in Poland in 2004-2008 compared with the previous period which is far beyond the scope of this paper. The results in terms of market potential and its evolution over time reflect the fact that there is a pattern of increasing agglomeration of economic activities in Poland over time.

This pattern of concentration of economic activities over time is in light with some of the predictions of core-periphery New Economic Geography Models (Krugman 1991a, 1991b) and is much less supportive of the predictions of neoclassical models of growth (Barro 1991, Barro and Sala-i-Martin, 1995).

\section{Theoretical Framework}

The theoretical foundations of our empirical estimations are based on Ottaviano and Pinelli's (2006) NEG Model who carried out an extension of a standard 2x2x2 core-periphery NEG Model such as Redding and Venables (2004), Breinlich (2006) incorporating labour mobility à la Hanson (1998) and Helpman (1998). We consider a world with regions $\mathrm{j}: 1 \ldots . . \mathrm{R}$ and we focus on the manufacturing sector, composed of firms that operate under increasing returns to scale and produce differentiated products. On the demand side, a typical individual in region $\mathrm{j}$ derives utility from consuming a set of horizontal differentiated goods $X_{j}$ and land services, $L_{j}$ ("housing") according to the following Cobb-Douglas utility function:

$U_{j}=X_{j}^{\mu} L_{j}^{1-\mu}, 0<\mu<1 . X_{j}=\left[\sum_{i=1}^{R} n_{i} x_{i, j}^{\frac{\sigma-1}{\sigma}}\right]^{\sigma / \sigma-1}$ is a CES quantity index of available variables at the disposal of individuals at location $j$ where $n_{i}$ is the number of firms in location $j, x_{i, j}$ is the country demand for a variety produced in $i, \sigma$ is the elasticity of substitution between any two varieties. The final demand in $i$ from location $j$ is given by the expression (1)

$$
x_{i, j}=p_{i j}^{-\sigma}\left[\sum_{n=1}^{R} n_{n} p_{n j}^{1-\sigma}\right]^{-1} Y_{j}
$$

If we define a price index for manufacturing goods as $P_{j}=\left[\sum_{n=1}^{R} n_{n} p_{n j}^{1-\sigma}\right]^{\frac{1}{1-\sigma}}$ and rewrite the expenditure on consumption as $E_{j}=Y_{j}$ the final demand in location $j$ can be given by $x_{i j}^{\text {cons }}=p_{i j}^{-\sigma} P_{j}^{\sigma-1} E_{j}$. However, in order for $x_{i j}^{\text {cons }}$ units to arrive, $T_{i, j} x_{i j}^{\text {cons }}$ units must be shipped. Thus effective demand facing a firm in $\mathrm{i}$ from $\mathrm{j}$ is given by expression (2)

$$
x_{i j}=T_{i j} p_{i j}^{-\sigma} P_{j}^{\sigma-1} E_{j}=p_{i}^{-\sigma} T_{i j}^{1-\sigma} P_{j}^{\sigma-1} E_{j}
$$

$P_{i, j}\left(P_{i, j}=P_{i} T_{i, j}, T_{i, j}\right.$ stands for iceberg transport cost, so $T_{i, j}=1$ the trade is costless, while $T_{i, j}-1$ measures the proportion of output lost in shipping from $i$ to $j$ ) is the price of varieties produced in $i$ and sold in $j$ and $Y_{j}$ is the total income in location $j$. 
Turning to the supply side, a representative country $i$ firm maximizes the following profit function:

$$
\prod_{i}=\sum_{n=1}^{R} p_{i} x_{i n}-w_{i}^{\alpha} r_{i}^{1-\alpha} c_{i}\left(F+x_{i}\right)
$$

where the total output of the firm is $x_{i} \equiv \sum_{j} x_{i, j}$. Technology has increasing returns to scale and its represented by a fixed output requirement $c_{i} F$ and a marginal input requirement $c_{i}$, parameters that can vary across regions. For our purpose, we suppose that we only need primary factors in the production of manufacturing goods, entering in the production function as a Cobb-Douglas form. Basically, we assume that we need labour (with price $w_{i}$ and input share $\alpha$ ) and land (with price $r_{i}$ and input share $1-\alpha$ ).

The first order conditions for profit maximization yield the standard result that equilibrium prices are $P_{i}=\frac{\sigma}{\sigma-1} w_{i}^{\alpha} r_{i}^{1-\alpha} c_{i}$. Substituting this pricing rule into the profit function we obtain the following expression for the equilibrium profit function $\Pi_{i}=\left(\frac{P_{i}}{\sigma}\right)\left[x_{i}-(\sigma-1) F\right]$. Free entry assures that long-run profits will be zero implying that $x_{i}=\bar{x}=\frac{\sigma-1}{F}$. The price needed to sell this many units satisfies $P_{i}^{\sigma}=\frac{1}{\bar{x}} \sum_{j=1}^{R} E_{j} G_{j}^{\sigma-1} T_{i, j}^{1-\sigma}$. Combining this expression with the fact that in equilibrium prices are a constant mark-up over marginal costs we obtain the following zero-profit condition which can be termed as the free entry condition (FE)

$$
\mathrm{FE}:\left[\left(\frac{\sigma}{\sigma-1}\right) w_{i}^{\alpha} r_{i}^{1-\alpha} c_{i}\right]^{\sigma}=\sum_{j=1}^{R} E_{j} P_{j}^{\sigma-1} T_{i, j}^{1-\sigma}
$$

According to equation (3), the nominal wage level in region $i$ depends on a weighted sum of purchasing power in all accessible regions $j$, whereby the weighting scheme is a function declining with increasing distance between locations $i$ and $j$. This sum we will refer to as the "market potential" of country $i(M P i)$. Equation (3) can be rewritten as: Where $w_{i}=A\left(M P_{i}\right)^{\frac{1}{\alpha \sigma}} r_{i}^{\frac{-\beta}{\alpha}} c_{i}^{\frac{-1}{\alpha}}$
$M P_{i}=\sum_{j=1}^{R} E_{j} P_{j}^{\sigma-1} T_{i, j}^{1-\sigma}$ is the "market potential" of region $i$. The meaning of this
equation is that access advantages raise local factor prices. More precisely, production equation is that access advantages raise local factor prices. Mores
sites with good access to major markets because of relatively low trade costs tend to reward their production factors with higher wages. 
Based on the assumption of labour mobility, workers would be indifferent among locations condition that they provide the same level of indirect utility V. Therefore, given a chosen level of utility $\mathrm{V}$, if we assume that the land is locally owned, the condition of free mobility (FM) can be expressed mathematically as:

$$
\text { (FM) } \frac{w_{i}}{r_{i}^{1-\mu}}=V
$$

Taking logs in expressions (4) and (5) it is possible to depict a graph which relates wages and land rents. Figure 6 shows this relationship where the downward slopping curve corresponds to the FE condition which shows combinations of wages and land rents that make firms indifferent between locations. If wages increase in order to be indifferent between two locations they would have to offset by paying less in land rents and vice versa. The upward sloping curve corresponds to the FM condition which shows combinations of wages and land rents that make workers indifferent between locations. In this case, if there is a positive shock in land rents in a location in order to achieve the same level of utility in that location and therefore continue to live there workers have to be compensated with higher salaries in order to keep the same level or real wages and vice versa. Therefore within this framework it is easy to simulate the potential impact on wages and land rents of a shock in market potential by looking at the displacement in the curves and the results in the new equilibrium. A positive shock in market potential only affects the curve derived from the FE condition shifting it up to a new equilibrium at higher wages and land rents. An increase in a location's market potential (ceteris paribus) increase its attractiveness both for firms and workers. Land values capitalize this situation since the increase flow of workers to the location experiencing an increase in market potential values will boost the bid for land and therefore a hiking up in land rents should be observed.

Figure 6

\section{Equilibrium Wages and Land Rents (Market potential shock)}

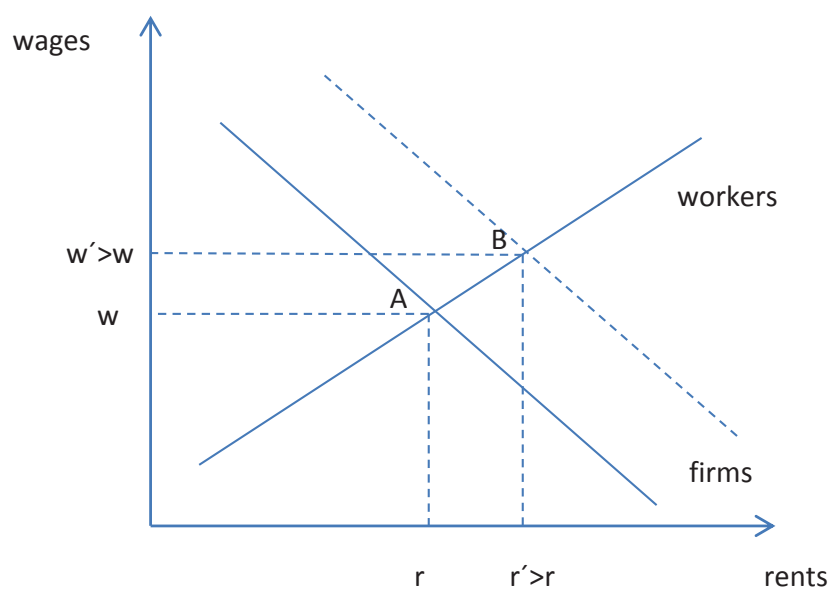

Source: Own elaboration based on Ottaviano and Pinelli (2006) 


\section{Market Potentials and Economic Growth in Poland}

The economic growth experienced in Poland in the recent past did not come along with a reduction in regional inequalities within the country; in fact it was quite the opposite. Taking the coefficient of variation as our measure of inequality, Figure 7 shows the evolution of per capita GDP disparities at NUTS 3 level in Poland from 1995 to 2008. As it can be seen in Figure 4, the evolution of regional inequalities over time in Poland witnessed a remarkable increase, especially from 1995 to 2001, then they seem to come to a halt from 2001 to 2003 and again they regain momentum from 2004 onwards. Taking only our initial and final year into account the increase in Polish per capita GDP inequalities measure by the coefficient of variation was $45.8 \%$.

Figure 7

Regional per Capita GDP Inequality: Poland NUTS 3 Regions

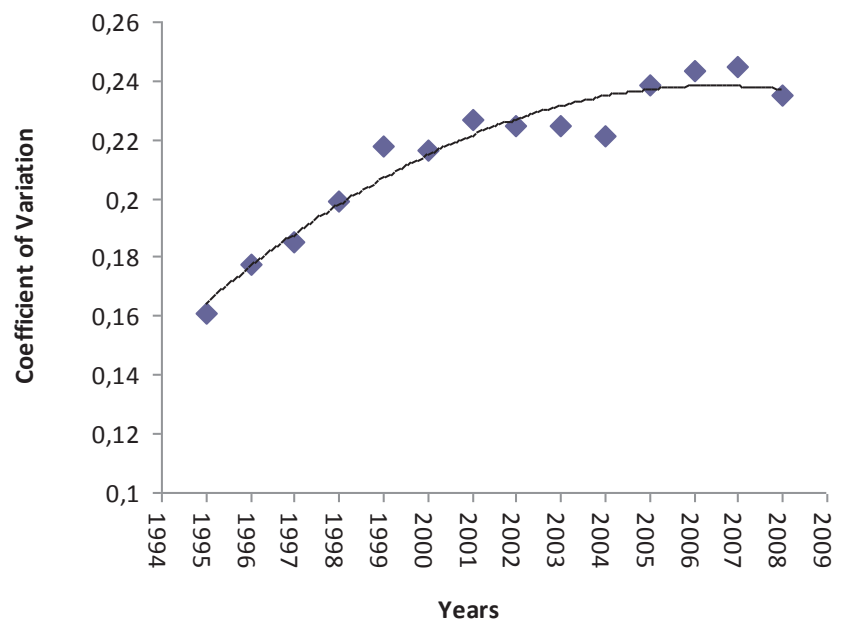

Source: Own elaboration based on Eurostat data.

What are the driving forces behind this evolution of regional income inequalities? At a theoretical level from the point of view of neoclassical growth models, their prediction is in favour of convergence in the long run where the main mechanism behind the process of convergence is the assumption of diminishing returns to scale in labour and capital implicit in the neoclassical production function. However since the beginning of the nineties, a new branch within the spatial economics, the so called New Economic Geography (Krugman, 1991, 1992) has emphasized the role of second nature geography factors $^{7}$ (access to consumer markets and to inputs suppliers) as a driving force behind

$7 \quad$ The term second nature geography refers to how far a country or regions is from its consumer markets or from its input suppliers whereas the term first nature geography refers to the physical geography of a country (access to navigable rivers, endowments of resources, sunshine hours, ruggedness, etc.) 
the agglomeration of economic activities in space and income inequalities. Within this framework, the combination of falling in transport costs with increasing returns to scale in manufacturing activities and the size of the market interact in a cumulative process which may lead to the spatial concentration of economy activities or in more technical words to an industrialized core and a deindustrialized periphery ${ }^{8}$. The empirical literature in NEG has triggered a plethora of contributions since the end of nineties on the pattern of the spatial concentration of economic activities by testing on of the main predictions of these models which is the relationship between market potentials and income levels for different scenarios ${ }^{9}$, a sample of world countries (Redding and Venables, 2004), counties within US (Hanson 2005), EU regions (Breinlich, 2006) etc.

Therefore taking into account the Polish market potential patterns analysed in the previous sections of this paper and the recent patterns in regional inequalities we can ask if accessibility (measured by our market potentials) played a role in the increase in regional inequalities during our period of analysis or in other words, can market potential to some extend explain the different growth rates in regional per capita income in Poland?

In order to shed light to these questions, we depart from Ottaviano and Pinelli's (2006) NEG Model outline in the previous section of this paper and we derive the structural equations which relate per capita GDP growth with market potentials as the main factor to explain the disparities observed in regional per capita incomes. Then we will estimate the structural equations of the model using Polish data for the period 1995-2008.

\subsection{Econometric approach}

The former analysis suggests that we can estimate the impact of market potentials on the growth of GDP per capita by estimating standard growth regressions and incorporating to them our market potential measure. We are going to estimate two different growth equations; one based on the incorporation of the initial conditions in both GDP per capita and market potential and another based on the incorporation of the initial conditions in GDP per capita and the changes in regional market potentials occurred in our period of analysis.

To estimate the relationship between the growth in GDP per capita and the initial GDP per capita levels and market potentials the following regression equations will be used:

$$
\log \left[y_{i, t+T} / y_{i, t}\right]=\alpha+\beta \log \left[y_{i, t}\right]+\gamma \log \left[M P_{i, t}\right]+u_{i t, t+T}
$$

8 For a comprehensive survey of NEG models see Combes et al. (2008), Baldwin et al. (2003), Brakman et al. (2001), Fujita et al. (1999), Fujita and Thisse (2002).

9 The testing of this relationship is known as the testing of the nominal wage equation which can be easily derived from a typical core-periphery $2 \times 2 \times 2$ NEG model. 
The term on the left-hand side of the equation is the growth of per capita GDP from the base year $t$ to the year $t+T$. Initial per capita GDP in region $i$ is given by $y_{i, t}$, initial market potential is given by $M P_{i, t}$ and $u_{i, t, t+T}$ is the disturbance term.

In order to estimate the effects of the changes in market potentials observed in Poland on the growth of GDP per capita the following regression equation will be used:

$$
\log \left[y_{i, t+T} / y_{i, t}\right]=\alpha+\beta \log \left[y_{i, t}\right]+\gamma \log \left[\Delta M P_{i, t, t+T}\right]+u_{i t, t+T}
$$

Where the only difference with the previous equation is the term $\Delta M P_{i, t, t+T}$ that represents the change in market potentials between the base year, $t$, and the year $t+T$.

\subsection{Data and regional system}

We are going to analyse the relationship between regional per capita GDP disparities in Poland and market potentials using cross regional data at NUTS 3 level for the 66 Polish regions for the period 1995-2008.

Regarding to market potential data, on the one hand we will compute market potential for the period 2000-2008 using GDP figures at current prices as a proxy for the numerator of the Harris (1954) market potential function and on the other we will compute additional regional market potential values going back until the year 1995 and moving forward to the year 2008. In this case we will use GDP figures expressed in $\mathrm{PPS}^{10}$ as the proxy for the numerator of the Harris (1954) expression. The data for the growth regressions comes from Eurostat, Cambridge Econometrics regional data bank and from the Polish Office for National Statistics.

\subsection{Regression results}

The results of the impacts of changing market potentials on regional per capita GDP growth in Poland are summarized in Tables 3 (variables measured at current prices) and 4 (variables measured in PPS). The first two columns of Table 3 contain the results of the estimation of equation (6) where regional per capita GDP growth in Polish regions in 2000-2008 has been regressed on 2000 values of regional per capita GDP and regional market potential using OLS (column 1) and IV (columns 2, 3, 4 and 5). The results of these estimations show that initial regional market potentials have a positive and statistically significant influence on the growth rates of the period whereas initial per capita GDP values they do not exert any influence on growth rates. In column 3 we perform the estimations for the period 2000-2008 analyzing instead the impact of changing market potentials on growth rates and in columns 4 and 5 we carried out the same analysis but splitting the sample period into two sub periods, 2000-2004 and 2004-2008.

10 See Sections 2, 3 and 4 for further details regarding to market potential computations. 
The overall results for 2000-2008 and for the two subsamples point to the fact that growing market potentials do indeed positively affect the regional growth in per capita GDP levels. However, the coefficients of the initial per capita GDP values for the three periods although turn out to be positive which would indicate the lack of convergence or catching up between Polish regions they are not statistically significant at the conventional critical values. Therefore, taking into account the results obtained in the previous sections of this paper where we pointed out to the fact that the largest changes in market potentials could be observed in the so called economic core regions of Poland, if, additionally, we have shown that changing in market potentials positively affect growth rates, a pattern of divergence in income levels among Polish regions should be expected. This is in fact the result as it can be seen in the pattern of increase in regional inequalities depicted in Figure 2. The same results have been obtained in the analysis of recent economic developments in the new member states (NMS) regions, which show that especially the capital cities have been outperforming other regions of the respective countries in terms of economic growth (Jasmand and Stiller 2005, Niebuhr and Schlitte 2008). Therefore, national growth rates in the NMS seem to be driven mainly by agglomeration processes. These patterns in terms of regional growth have been observed in cohesion countries during earlier enlargement rounds of the EU (see European Commission, 2004).

Table 4 summarizes the results of estimating the impact of changing market potentials and initial levels of per capita GDP on the regional per capita GDP growth of Polish regions (Equation 7) for the period 1995-2008, 2000-2008, 2000-2004 and 2004-2008 (columns 1, 2, 3 and 4, respectively) using PPS values for the variables included in the regressions.

Overall, the results are in line with the previous ones. For the period 1995-2008 we do not find any significant effect of the initial level of income in the subsequent rates of per capita GDP growth. On the contrary, the effect of changing market potentials on per capita GDP growth is positive and statistically significant. Therefore this result shows that changes in market potential do not support a process of convergence among regions in Poland in the period under analysis based on the fact the higher increases in market potential are realized in the so called economic core regions, the ones that are already the richer regions.

In order to compare the results of Table 4 with the previous ones we have also carried out the estimations for the period 2000-2008 and for the two sub periods 2000-2004 and 2004-2008. The results show again that there is a positive relationship between changing market potentials and per capita GDP growth across the three periods analysed. With regard to the effects of the initial levels of per capita GDP on the rates of growth, we found that the coefficients are negative but they are not statistically significant at the conventional critical levels of $1 \%$ or $5 \% .^{11}$

11 The coefficients on the initial levels of per capita GDP are significant at $10 \%$ levels for the period 2000-2008 and for the sub period 2000-2004. 
Table 3

Market Potential and Regional Growth (I)

\begin{tabular}{|c|c|c|c|c|c|}
\hline \multirow{3}{*}{$\begin{array}{l}\text { Dependent Variable } \\
\text { Regressors } \\
\end{array}$} & \multicolumn{5}{|c|}{ per capita GDP Growth } \\
\hline & \multicolumn{2}{|c|}{$2000-2008$} & \multirow{2}{*}{$\frac{2000-2008}{(3)}$} & \multirow{2}{*}{$\begin{array}{c}2000-2004 \\
(4)\end{array}$} & \multirow{2}{*}{$\begin{array}{c}2004-2008 \\
(5)\end{array}$} \\
\hline & (1) & (2) & & & \\
\hline Constant & $\begin{array}{r}-0.15 \\
(0.21)\end{array}$ & $\begin{array}{l}-0.32 * \\
(0.15)\end{array}$ & $\begin{array}{c}-0.58 * \\
(0.15)\end{array}$ & $\begin{array}{l}-0.25 \\
(0.07) \\
\end{array}$ & $\begin{array}{c}-0.32 * \\
(0.14)\end{array}$ \\
\hline Log per capita GDP 2000 & $\begin{array}{l}-0.02 \\
(0.05)\end{array}$ & & $\begin{array}{c}0.03 \\
(0.03)\end{array}$ & $\begin{array}{l}0.008 \\
(0.01)\end{array}$ & \\
\hline Log MAGDP2000 & $\begin{array}{l}0.14^{* *} \\
(0.04)\end{array}$ & $\begin{array}{l}0.15^{* *} \\
(0.04)\end{array}$ & & & \\
\hline Log inc MAGDP2000-2008 & & & $\begin{array}{c}3.1^{* *} \\
(0.48)\end{array}$ & & \\
\hline Log inc MAGDP2000-2004 & & & & $\begin{array}{l}3.65^{* *} \\
(0.71)\end{array}$ & \\
\hline Log inc MAGDP2004-2008 & & & & & $\begin{array}{l}2.85^{* *} \\
(0.50)\end{array}$ \\
\hline Log per cápita GDP 2004 & & & & & $\begin{array}{c}0.03 \\
(0.02)\end{array}$ \\
\hline Estimation & OLS & IV & IV & IV & IV \\
\hline $\mathbf{R 2}$ & 0.53 & 0.49 & 0.70 & 0.72 & 0.55 \\
\hline Prob (F-statistic) & 0.00 & 0.00 & 0.00 & 0.00 & 0.00 \\
\hline Number observations & 66 & 66 & 66 & 66 & 66 \\
\hline
\end{tabular}

Note: Table displays coefficients for OLS estimations and Huber-White heterocedasticity robust standard errors in parenthesis. The dependent variable is the log of per capita GDP growth in the years 2000-2008 (columns 1, 2 and 3) and the log of per capita GDP growth in the years 2000-2004 (column 4) and 2004-2008 (column 5). LogMAGDP2000, is the logs of market access in the years 2000, Log inc MAGDP2000-2008, 2000-2004 and 2004-2008 are the percentage increases in market access between 2000-2008, 2000-2004 and 2004-2008, respectively. IV estimation is based on the use of the average distance between regions. For data sources see text and appendix A.

${ }^{*}$ and ${ }^{* *}$ signify statistical significance at the $5 \%$ and $1 \%$ levels

These results suggest that per capita GDP growth in Polish regions is strongly affected by the changing market potentials. Therefore as these changes in market potential are more important in the so called economic core regions (central regions in economic terms) than in peripheral ones, a pattern of cumulative effects of increasing market potentials and income levels in these regions should be expected with the side effect of increasing in regional disparities as has been shown in Figure 4. 
Table 4

Market Potential and Regional Growth (II-PPS values)

\begin{tabular}{|c|c|c|c|c|}
\hline \multirow[t]{2}{*}{ Dependent Variable } & \multicolumn{4}{|c|}{ per capita GDP Growth } \\
\hline & 1995-2008 & 2000-2008 & 2000-2004 & 2004-2008 \\
\hline Regressors & (1) & (2) & (3) & (4) \\
\hline Constant & $\begin{array}{r}-0.04 \\
(0.39)\end{array}$ & $\begin{array}{l}0.16^{* *} \\
(0.04)\end{array}$ & $\begin{array}{l}0.07^{+* *} \\
(0.03)\end{array}$ & $\begin{array}{l}0.08 \\
(0.02)\end{array}$ \\
\hline Log per capita GDP 1995 & $\begin{array}{c}0.06 \\
(0.09)\end{array}$ & & & \\
\hline Log inc MAGDP1995-2008 & $\begin{array}{l}0.29^{* *} \\
(0.04)\end{array}$ & & & \\
\hline Log per capita GDP 2000 & & $\begin{array}{c}-0.35^{* * *} \\
(0.01)\end{array}$ & $\begin{array}{c}-0.011^{* * *+} \\
(0.00)\end{array}$ & \\
\hline Log inc MAGDP2000-2008 & & $\begin{array}{l}0.99 * \\
(0.07)\end{array}$ & & \\
\hline Log inc MAGDP2000-2004 & & & $\begin{array}{l}1.08^{* *} \\
(0.04)\end{array}$ & \\
\hline Log inc MAGDP2004-2008 & & & & $\begin{array}{l}1.01^{* *} \\
(0.08)\end{array}$ \\
\hline Log per capita GDP 2004 & & & & $\begin{array}{l}-0.01 \\
(0.00)\end{array}$ \\
\hline Estimation & IV & IV & IV & IV \\
\hline $\mathbf{R 2}$ & 0.57 & 0.83 & 0.88 & 0.92 \\
\hline Prob (F-statistic) & 0.00 & 0.00 & 0.00 & 0.00 \\
\hline Number observations & 66 & 66 & 66 & 66 \\
\hline
\end{tabular}

Note: Table displays coefficients for OLS estimations and Huber-White heterocedasticity robust standard errors in parenthesis. The dependent variable is the log of per capita GDP growth in the years 1995-2008 (columns 1), 2000-2008 (column 2), 2000-2004 (column 3) and 2004-2008 (column 4). Log inc MAGDP 1995-2008, 2000-2008, 2000-2004 and 2004-2008 are the percen-tage increases in market access between 1995-2008, 2000-2008, 2000-2004 and 2004-2008, respectively. IV estimation is based on the use of the average distance between regions. For data sources see text and appendix A. * , ** and ${ }^{* * *}$ signify statistical significance at the $1 \%, 5 \%$ and $10 \%$ levels

\section{Concluding Remarks}

In this paper we analyse how changing market potentials have influenced the increasing pattern of per capita GDP disparities observed in Poland over the period 1995-2008. The theoretical rationale behind this analysis is based on Ottaviano and Pinelli (2006) New Economy Geography Model, where they derived the relationship between growth in wages and market potentials. We then move on estimating growth-type regressions including as our key variable the changing in market potentials observed in the period under analysis. The estimations have been carried out for the 66 NUTS 3 Polish regions 
with data expressed in current values (2000-2008) and also with data converted at PPS values (1995-2008). ${ }^{12}$

Overall the results show that there is a very significant effect of the changing market potentials on per capita GDP growth across the different periods analysed in the paper. Therefore taking into account the pattern of changes that have occurred in market potentials across Polish regions described in the first part of the paper, this implies that the so called economic core regions in Poland have been the ones that have experienced the fastest rates of growth. Therefore the already relative rich regions tend to benefit more from the observed changes in market potentials than the poorest ones. This result works against the catching-up process on the Polish poorest regions to the income levels of the richest ones. Moreover, the inclusion in the estimated growth regressions of the initial levels of per capita GDP turn out to be no significant for the rates of growth of per capita GDP in the different periods analysed and once again reinforcing the pattern of increasing disparities observed in the income levels across Polish regions.

Finally, the process already described, in a New Economic Geography fashion, reflects the superior effects of the centripetal forces versus centrifugal ones that tend to agglomerate the economic activity in the so called economic core locations of the country and which may lead to cumulative effects of increasing income levels and market potentials in these regions and therefore a lack of convergence across regions. Therefore, as economic activities in Poland tend to concentrate over time, it is important to put into practice some policy measures to counterbalance the relative higher strength of centripetal forces with respect to the centrifugal ones and achieve a more balance development across the whole Polish territory. However, some scholars would argue that the "centripetal forces" would possible lead to higher efficiency and higher output of the economy as a whole (albeit at a price of higher regional disparities). However, the main reason why we think regional disparities should be counterbalanced resides in the fact that in environments of free labour mobility, those regions which are lagging behind would face to a continuous fall in the labour force, especially the highly qualified ones, who would migrate to regions with higher wages and better living conditions. Thus, in the long run the risks of potentially losing a significant share of economic activities in these territories would be very high and this would eventually lead to the abandon by the citizens of their regions. The subsequent concentration of population and activities in big metropolitan regions would increase congestion and pollution and would give rise to an increase in the costs of living which could not be afforded by everyone. These outcomes are clearly no desirable. At this point the European Union regional policy and the own Polish policies should play a major role in even out the development levels across Poland.

Our results and conclusions are based on the analysis of Poland as an "isolated" country or "closed" economy which of course constitutes a limitation of our analysis. However, is very well known the fact that Poland is an open economy and a part of the single market which interacts and trade with other surrounding locations (non-Polish ones)

12 Data availability in PPS values allow us to extend the period of analysis five years back. 
and foreign countries. The inclusion of other European Union regions and countries in the analysis carried out here would have had an impact in terms of market potential computations and also on the quantitative results although the qualitative conclusions would remain the same. Overall, all Polish regions would have increased their market potential by the simple fact that we are adding up GDPs of other locations weighted by the inverse of distance. However, in relative terms, those regions which would have benefited the most of this enlargement of the scope of market potential computations would be those located in the Western and South-Western parts of Poland since they are closer to the most advanced regions and countries of the former EU15 (Germany) and other richer countries. Thus, in terms of results, the strong agglomeration pattern we have observed in our analysis would not be alleviated by the enlargement of the spatial scope to take on board other regions and countries. More on the contrary, the core-periphery pattern would be reinforced after the inclusion of other non-Polish regions meaning that the agglomeration forces would definitely take the lead over the dispersion ones.

\section{References}

Baldwin, R. E., Forslid, R., Martin, P., Ottaviano, G., Robert-Nicoud, F. (2003), Economic Geography and Public Policy. Princeton, NJ: Princeton University Press.

Barro, R. (1991), "Economic Growth in a Cross-Section of Countries." Quarterly Journal of Economics, Vol. 106, No. 2, pp. 407-443.

Barro, R., Sala-i-Martin, X. (1995), Economic Growth. New York: McGraw-Hill.

Brakman, S. Garretsen, H., Van Marrewijk, C. (2001), An Introduction to Geographical Economics. Cambridge University Press.

Breinlich, H. (2006), "The Spatial Income Structure in the European Union - What Role for Economic Geography?" Journal of Economic Geography, Vol. 6, No. 5, pp. 593-617.

Combes P-P. et al. (2008), Economic Geography. Princeton: Princeton, University Press.

Clark, C., Wilson, F., Bradley, J. (1969), "Industrial Location and Economic Potential in Western Europe." Regional Studies, 3. pp. 197-212.

Crafts, N. (2005), "Market Potential in British Regions 1871-1931." Regional Studies, Vol. 39, No. 9 , pp. 1159-1166

Dicken, P., Lloyd, P. (1977), Location in Space. New York: Harper and Row.

European Commission (2004), "A New Partnership for Cohesion. Convergence, Competitiveness, Cooperation." Third Report on Economic and Social Cohesion, Luxembourg.

Fujita M., Thisse, J-F. (2002), Economics of Agglomeration: Cities, Industrial Location and Regional Growth. Cambridge, UK: Cambridge University Press.

Fujita M. et al. (1999), The Spatial Economy. Cambridge MA: MIT Press.

Hanson, G. (2005), "Market Potential, Increasing Returns and Geographic Concentration." Journal of International Economics, Vol. 67, No. 1, pp. 1-24.

Harris, C. (1954), "The Market as a Factor in the Localization of Industry in the United States." Annals of the Association of American Geographers, Vol. 64 (1954), pp. 315-348.

Jasmand, S., Stiller, S. (2005), "Capital Cities in the New EU-States - Current Trends and Economic Status Quo." Intereconomics, Vol. 38, No. 5, pp. 298-305.

Keeble, D., Owens, P. L., Thompson, C. (1982), "Regional Accessibility and Economic Potential in the European Community." Regional Studies, Vol. 16, No. 6, pp. 419-432. 
Krugman, P. (1991a), Geography and Trade. Cambridge MA: MIT Press.

Krugman, P. (1991b), "Increasing Returns and Economic Geography." Journal of Political Economy, Vol. 99, No. 3, pp. 483-99.

López-Rodríguez J., Faiña, A. (2007), "Regional Wage Disparities in the European Union: What Role for Market Access." Investigaciones Regionales, No. 11, pp. 5-23, 2007.

López-Rodríguez, J., Faiña, J. A., Lopez Rodriguez, J. (2007), "Human Capital Accumulation and Geography: Empirical Evidence from the European Union." Regional Studies, Vol. 41, No. 2, pp. 217-234.

López-Rodríguez, J. Faiña, J., Bolea-Gabriel, C. (2011), "Economic Remoteness and Wage Disparities in Romania." Tijdschrift voor economische en sociale geografie, Vol. 102, No. 5, pp. 594-606.

Martinez Galarraga, J. (2010), "Market Integration and Regional Inequality in Spain, 1860-1930." $\mathrm{PhD}$ Thesis, University of Barcelona.

Midelfart, K. H., Overman, H. G., Redding, S. J., Venables, A. J. (2002), "Integration and Industrial Specialisation in the European Union." Revue Economique, Vol. 53, No. 3, pp. 469-481.

Niebuhr, A. (2006), "Market Access and Regional Disparities. New Economic Geography in Europe." The Annals of Regional Science, Vol. 40, No. 2, pp. 313-334.

Ottaviano, G. I. P, Pinelli, D. (2006), "Market Potential and Productivity: Evidence from Finnish Regions." Regional Science and Urban Economics, 2006, Vol. 36, No. 5, pp. 636-657.

Redding, S., Schott, P. (2003), "Distance, Skill Deepening and Development: Will Peripheral Countries Ever Get Rich?” Journal of Development Economics, Vol. 72, No. 2, pp. 515-41.

Redding, S., Venables, A. J. (2004), "Economic Geography and International Inequality", Journal of International Economics. Vol. 62, No. 1, pp. 53-82.

Wolszczak-Derlacz, J. (2010), "Does One Currency Mean One Price? An Analysis of the Euro Effect on Price Dispersion and Convergence." Eastern European Economics, Vol. 28, No. 2,

pp. $87-114$. 